Cuadernos de Lingüística Hispánica $n^{\circ} .24$ ISSN 0121-053X • ISSN en línea 2346-1829 Julio-Diciembre 2014, pp. 13-24

\title{
Lección de lingüística. Consideraciones en torno de Ferdinand De Saussure: Asidero de la lingüística actual*
}

CÉSAR A. ROMERO FARFÁN"*

carfarfan@gmail.com

Recepción: 03 de marzo de 2014

Aprobación: 12 de mayo de 2014

Cómo citar este artículo: Romero Farfán, C. (2014). Lección de Lingüística. Consideraciones en torno de Ferdinand De Saussure: Asidero de la lingüística actual. Cuadernos de Lingüística Hispánica, 24, 13-24. Tunja: Uptc.

* Artículo de reflexión. Fue revisado, inicialmente, por el profesor Joselyn Corredor T. Hoy es parte de sus cursos universitarios de Lingüística en el pregrado y en el posgrado. Es un componente del marco teórico general del grupo de investigación EPISTEME, reconocido por COLCIENCIAS.

** Profesor y director de la Escuela de Idiomas de la Universidad Pedagógica y Tecnológica de Colombia. 


\title{
Resumen
}

Este artículo es una lección de Lingüística. Parte de citas tomadas del Curso de Lingüística general. En este trabajo se reflexiona y se añade principios estructuralistas que, actualmente, son parte de la ciencia del lenguaje. Pretende ser material de una clase básica de Linguística. No profundiza en conceptos, pero sí los contextualiza. El estilo es sencillo porque se busca el máximo entendimiento posible por parte de estudiantes universitarios.

Palabras clave: estructuralismo lingüístico, dicotomías lingüísticas, lingüística de la lengua.

\section{Lesson on Linguistics. Considerations on Ferdinand De Saussure: current pillar of linguistics.}

\begin{abstract}
This article is a lesson on linguistics. It begins with quotations from the Course on General Linguistics and contains reflections and additions to the structuralist principles that currently form part of the science of language. It aims at becoming material for a basic class on linguistics. It does not delve into concepts, but does provide contexts for them. The writing style is simple because college students' highest understanding is sought.
\end{abstract}

Key words: Linguistic structuralism, linguistic dichotomies, linguistics of language. 


\section{Leçon de Linguistique. Des considérations autour de Ferdinand De Saussure: appui de la linguistique actuelle}

\section{Résumé}

Cet article est une leçon de linguistique. Il part de citations prises du Cours de Linguistique Générale. Dans ce travail on réfléchit et on ajoute des principes structuralistes qui, dès nos jours, font partie de la science du langage. Le travail prétend être le matériel d'un cours de linguistique de base. On n'approfondit pas de concepts, mais on les contextualise. Le style de présentation est simple parce que l'on cherche la plus grande compréhension possible de la part des étudiants universitaires.

Mots clés: structuralisme linguistique, dichotomies linguistiques, linguistique de la langue.

\section{Lição de Linguística. Considerações em torno de Ferdinand De Saussure: apoio da linguística atual}

\section{Resumo}

Este artigo é uma lição de linguística. Parte de citações tomadas do Curso de Linguística Geral. Neste trabalho é feita uma reflexão e se acrescentam princípios estruturalistas que, atualmente, são parte da ciência da linguagem. Pretende ser material de uma aula básica de Linguística. Não aprofunda em conceitos, mas sim os contextualiza. 0 estilo é simples porque se busca o máximo entendimento possível por parte de estudantes universitários.

Palavras chave: estruturalismo linguístico, dicotomias linguísticas, linguística da língua. 


\section{Introducción}

El artículo que presentamos a continuación se ha constituido en material de trabajo de la opción temática Lingüística general, adscrita a los planes de estudio de Idiomas Modernos, Lenguas Extranjeras y Comunicación Social, de algunas universidades tunjanas y bogotanas. Prontos a cumplir 100 años de la publicación del Curso de Lingüística general, vademécum de la actual ciencia del lenguaje, es menester recordar cómo De Saussure, sus discípulos, y algunos de quienes los han seguido, realmente sentaron las bases del estudio científico, social y sistémico de la lengua, colegida del lenguaje y subsumida en el habla.

\section{Consideraciones liminares}

Como insistimos vehementemente en el desarrollo de nuestras clases de Lingüística, la aparición del Curso de lingüística general, en 1916, como producto del trabajo de compilación, dilucidación y escritura de los estudiantes de Ferdinand De Saussure, coincide con el advenimiento de la ciencia del lenguaje como tal, pronta a cumplir 100 años. Recordemos que una ciencia es, precisamente, ciencia, cuando tiene un objeto de estudio -en el caso de la Linguística de 1916, lo era la lengua; en la Linguística actual es el lenguaje-, un método científico, un estatuto epistemológico y una tradición científica-para la Lingüística, lo fue la Gramática, la Filología, y la Filología comparada-.

De modo significativo, la figura clave en el cambio de la actitud del siglo XIX a la del XX fue el lingüista suizo Ferdinand De Saussure, quien, tras estudiar en Leipzig con miembros de la escuela neogramática, se dio a conocer [...] mediante una importante contribución a la lingüística comparativa indoeuropea. Aunque él mismo publicó poco, sus lecciones de comienzos del siglo sobre lingüística impresionaron tanto a algunos de sus alumnos de París y Ginebra que en 1916 publicaron su Cours de linguistique générale tal como lo pudieron reconstruir a partir de las notas tomadas por ellos y por otros y de materiales conservados de manos de Saussure. En la historia de la linguística, Saussure es, en gran medida, conocido y estudiado a través de lo que sus alumnos recogieron (Robins, 2000, pp. 271-272). 
Pues bien, es interesante enterarnos de cómo unos estudiantes, fieles a su maestro y admiradores de él, son los responsables de la publicación del Curso, obra que, como ya lo advertimos, independiza a la Lingüística de la Filosofía y de la Lógica, ciencias de las que por siglos fue subsidiaria; inclusive, la obra de los alumnos de Saussure nos permite, hoy por hoy, diferenciar una actitud lingüística frente a una gramatical; la primera muy cercana a lo científico; la segunda, a no ser por el Generativismo lingüístico, más prescriptiva.

Recordemos aquí que la Gramática no es solamente la disciplina del buen escribir; con el Generativismo lingüístico, pero previamente con el cartesianismo, ya desde el siglo XVIII, lo gramatical es capacidad para producir y generar elementos u oraciones propias de una lengua. Precisamente, lo agramatical implica el desconocimiento de la estructura propia de una lengua, de su orden, de su forma, de su función, de su funcionamiento, y de sus paradigmas.

Siguiendo con el ginebrino, de acuerdo con Bernal (2008, p. 277 y ss):

Saussure sentó las bases de la ciencia del lenguaje. "La aparición de Saussure en el panorama de los estudios sobre el lenguaje fue definitiva para que la Linguística se desligara de sus hermanas mayores -la Filosofía, la Filología comparada y la Historia- y se lanzara a deambular por sí sola.

$[\ldots]$

El estructuralismo surgió como corriente revitalizadora de excepcional importancia, que cobijó los estudios sobre el lenguaje y llegó a técnicas en extremo refinadas para describir los diversos niveles de la lengua.

Por tanto, pese a polémicas de gran interés en torno de lo fieles que fueran los estudiantes de Saussure, responsables del trabajo de composición y redacción del Curso: Charles Bally y Albert Sechehaye, quienes contaron con la colaboración de su esposa y, principalmente, de Albert Riedlinger ${ }^{1}$, es innegable que el libro es el responsable y elemento convergente de estudios lingüístico científicos, así como de deslindar tareas, objeto, métodos y conexiones de la Lingüística con otras ciencias.

Recordemos que la Filología comparada, una etapa vital y previa al advenimiento de la Lingüística, estudió histórica y comparadamente las lenguas, con la pretensión de encontrar la denominada "lengua madre" o "lengua primera". El sánscrito fue uno de sus mayores logros, como lengua génesis y origen de troncos y familias lingüísticas. Sin embargo, extrañamos hoy los estudios filológicos (o diacrónicos) de las lenguas. Como dirían varios lingüistas: desde los años ochenta - especialmente en Colombia- nos dedicamos a estudiar la lengua desde lo temporal, desde lo limitado en el tiempo, desde los corpus o cuerpos de la misma; olvidamos su relevancia

\footnotetext{
1 Una nota interesante sobre el particular, así como la reseña de una de las últimas obras publicadas por Saussure, en 2002, intitulada: "Écrits de linguistique générale", puede leerse en: Mahecha, M. Á. Ferdinand De Saussure. Écrits de linguistique générale. Sección Reseñas de Forma y Función. Bogotá: Universidad Nacional de Colombia, Número 16 (diciembre, 2005), pp. 310-323.
} 
en lo histórico y la manera como muchos elementos lingüísticos que parecerían desaparecidos vuelven, gracias al uso: juez y árbitro del idioma (cfr. Rosenblat y Sanabria, 1968).

Hoy, gozamos de los privilegios de una lingüística del habla: la Textolingüística, lo cual es plausible, sin dejar de extrañar los apuntes históricos tan importantes para corregir imprecisiones notables. Vayamos al caso de «vuestra merced», yuxtapuesto a "sumerced", cuyo origen, tan complejo, suele hacer creer a los colombianos, que las expresiones nacieron en Boyacá o, a lo sumo, en Santander. No es así:

Se sabe que vuestra merced, por su origen y por las personas a quienes iba dirigido, fue, en sus comienzos [españoles y portugueses], tratamiento excesivamente formalista y distanciado formalismo que, aunque mitigado, se nos antoja aún vigente en usted. Tan distante se sentía en sus comienzos el vuestra merced que hubo necesidad, como sabemos, de acudir, por algún tiempo, a él como escalón intermedio entre vuestra merced y vos.

Si comparáramos lo ocurrido en el español, en este campo, con otras lenguas, encontramos que, por ejemplo, en inglés you y en francés vous no aparecen tan distanciadores por haber asumido (más el you inglés que el vous francés) ciertos matices del thou (hoy prácticamente desaparecido) y del $t u$. Se puede afirmar, sin mayores posibilidades de error, que el you es, hoy por hoy, un pronombre igualador y que vous parece seguir la misma tendencia (Del Castillo, 1982, p. 639).

\section{De la materia, tareas y conexiones de la Lingüística}

Sobre el particular, acudamos textualmente al Curso mismo y recordemos varios de sus aforismos :

La materia de la lingüística está constituida en primer lugar por todas las manifestaciones del lenguaje humano, ya se trate de pueblos salvajes o de naciones civilizadas, de épocas arcaicas, clásicas o de decadencia, teniendo en cuenta, en cada período, no solamente el lenguaje correcto y el "bien hablar", sino todas las formas de expresión. Y algo más aún: como el lenguaje no está las más veces al alcance de la observación, el lingüista deberá tener en cuenta los textos escritos, ya que son los únicos medios que nos permiten conocer los idiomas pretéritos o distantes.

He aquí uno de las limitaciones y bondades, a la vez, del estructuralismo lingüístico: darle al lingüista la potestad de ir más allá de la prescripción gramatical -Gramática normativa- y describir la lengua mediante niveles de análisis -fonético-fonológico y morfológico, primero; semántico, luego con el generativismo; y pragmático enseguida con

2 La referencia bibliográfica que regirá la cita textual, sólo dividida por nuestras consideraciones, será: De Saussure, F. (1945). Curso de lingüística general. Buenos Aires: Losada, pp. 29-59. 
la Textolinguística; para llegar, hoy por hoy, al cognitivo y al simbólico, con la Semiología y la Linguística cognitiva-.

La tarea de la Lingüística será:

a) hacer la descripción y la historia de todas las lenguas de que pueda ocuparse, lo cual equivale a hacer la historia de las familias de lenguas y a reconstruir en lo posible las lenguas madres de cada familia;

b) buscar las fuerzas que intervengan de manera permanente y universal en todas las lenguas, y sacar las leyes generales a que se puedan reducir todos los fenómenos particulares de la historia;

c) deslindarse y definirse ella misma.

La Lingüística tiene conexiones muy estrechas con varias ciencias, unas que le dan datos, otras que se los toman. Los límites que la separan de ellas no siempre se ven con claridad. Por ejemplo, la Lingüística tiene que diferenciarse cuidadosamente de la etnografía y de la prehistoria, donde el lenguaje no interviene más que a título de documento; tiene que distinguirse también de la antropología, que no estudia al hombre más que desde el punto de vista de la especie, mientras que el lenguaje es un hecho social. [...] En el fondo todo es psicológico en la lengua, incluso sus manifestaciones materiales y mecánicas, como los cambios fonéticos; y puesto que la Linguística suministra a la Psicología social tan preciosos datos ¿no formará parte de ella? Éstas son cuestiones que aquí no hacemos más que indicar para volver a tomarlas luego.

Las conexiones de la Lingüística con la Fisiología no son tan difíciles de desenredar: la relación es unilateral, en el sentido de que el estudio de las lenguas pide aclaraciones a la Fisiología de los sonidos, pero no se las proporciona a su vez. En todo caso, la confusión entre las dos disciplinas es imposible: lo esencial de la lengua -ya lo veremos- es extraño al carácter fónico del signo lingüístico.

En cuanto a la Filología, ya hemos llegado a un acuerdo seguro: es netamente distinta de la Lingüística, a pesar de los puntos de contacto de las dos ciencias y de los servicios mutuos que se prestan.

Como podemos colegir del fragmento anterior, tomado textualmente del Curso, sus autores deslindan los conceptos de lenguaje y lengua; de otro lado, implícitamente, le restan al "buen hablar" todo un valor inconmensurable, como único campo o plano para estudiar el lenguaje; por el contrario, le insisten al lingüista en la necesidad de describir -actitud descriptiva- los hechos de la lengua, acorde con los niveles de la misma.

De otro lado, en buen momento, Saussure se adelanta a la actual Linguística del lenguaje: Psicolingüística y Sociolingüística en sus orígenes. Estas líneas del Curso, per se, 
nos plantean, como queda escrito, al lado de la Lingüística de la lengua, una Lingüística del lenguaje -especialmente, cuando se trata de las conexiones de la Linguística con otras ciencias-. No obstante, los estructuralistas son muy cuidadosos con esta materia de la Lingüística (insisten en dejarlo "apenas planteado"). Otro punto por analizar es el del centramiento en la lengua escrita; infortunadamente, esa sería una de las primeras críticas a Saussure y a sus intérpretes: el descuido de la lengua oral que, actualmente, parece ser una preocupación mayor de la ciencia del lenguaje.

\section{Finalicemos con:}

¿Y cuál es la utilidad de la Lingüística? Pocas personas tienen sobre esto ideas claras. No es este el lugar de fijarlas; pero es evidente, por ejemplo, que las cuestiones linguísticas interesan a todos cuantos -historiadores, filólogos, etc.- tienen que manejar textos. Más evidente todavía es su importancia para la cultura general: en la vida de los individuos y la de las sociedades no hay factor tan importante como el lenguaje. Sería inadmisible que su estudio no interesara más que a unos cuantos especialistas: de hecho, todo el mundo se ocupa del lenguaje, poco o mucho; pero -consecuencia paradójica del interés que se le presta- no hay terreno donde hayan germinado más ideas absurdas, prejuicios, espejismos, ficciones. Desde el punto de vista psicológico, esos errores no son desdeñables; pero la tarea del lingüista es ante todo la de declararlos y disiparlos tan completamente como sea posible.

Cierto, infortunadamente, frente a la Lingüística, la actitud gramatical normativa -prescriptiva- es aún muy fuerte en el imaginario de hablantes, oyentes, profesores y profesionales. Los alumnos que acuden a un curso sobre la ciencia del lenguaje suelen creer que aprenderán a hablar correctamente. No olvidemos una de las utilidades, a más de las enumeradas en la cita: retomemos el adverbio "pertinentemente": la pertinencia lingüística es uno de los hallazgos y de las preocupaciones más importantes de la Lingüística de hoy (intención e intensión comunicativas: la primera consciente e inconsciente; la segunda, necesaria en el momento de convencer y, luego, para persuadir)

\section{Objeto de la linguíística; la Semiología}

Prosiguiendo con los aforismos más significativos del Curso, en este contexto, los estructuralistas presentan una discusión importante en la relación lenguaje-lengua; leámosla:

¿Cuál es el objeto a la vez integral y concreto de la Lingüística?

$[\ldots]$

Pero ¿qué es la lengua? Para nosotros, la lengua no se confunde con el lenguaje: la lengua no es más que una determinada parte del lenguaje, aunque esencial. Es a la vez un producto social de la facultad del lenguaje y un conjunto de convenciones necesarias adoptadas por el cuerpo social para permitir el ejercicio de esa facultad 
en los individuos. Tomado en su conjunto, el lenguaje es multiforme y heteróclito; a caballo en diferentes dominios, a la vez físico, fisiológico y psíquico, pertenece además al dominio individual y al dominio social; no se deja clasificar en ninguna de las categorías de los hechos humanos, porque no se sabe cómo desembrollar su unidad (Ibídem, De Saussure, p. 37).

Con lo anterior, podemos concluir que, según el estructuralismo lingüístico, el objeto de estudio de la Linguística es la lengua, como un hecho social, desprendida del lenguaje como una facultad única y exclusiva de la especie humana; heteróclito porque en su origen concurren disímiles génesis, elementos, órganos, capacidades, destrezas, contextos, funciones cerebrales, entre otras. Abigarrado porque ni siquiera los hermanos, en una familia tradicional, habiendo crecido en un contexto análogo, manejan las mismas capacidades orales, escritas, de oratoria, persuasivas, práxicas, contextuales; en fin, discursivas (recordemos el amplio concepto de discurso, de la Lingüística del texto, en contraposición con el de discurso como uso oral exclusivo, proveniente de la tradicional oratoria y retórica).

Más adelante, frente a esta realidad, se le endilgará al habla, uso de la lengua, un carácter individual; en oposición a ello, con los años, ya lo escribimos, el habla se tipificará como una entidad individuo-social: "Al separar la lengua del habla (langue et parole), se separa a la vez: $1^{\circ}$ lo que es social de lo que es individual; $2^{\circ}$ lo que es esencial de lo que es accesorio y más o menos accidental" (ibídem, p. 41).

Con el transcurrir de las escuelas lingüísticas, luego de que el estructuralismo lingüístico es lingüística de la lengua, el generativismo será lingüística del lenguaje y la Textolingüística, insistimos, lingüística del habla. En ciertas ocasiones, allende esta consideración nos quedamos con la individualidad del habla; sí en efecto, el habla puede ser primero individual pero, con el crecimiento lingüístico del humano, con la complejización de su facultad de lenguaje, el habla se torna social, informal, no escrita o escrita entre comitas.

Más adelante, con el título de "Lugar de la lengua en los hechos humanos: la Semiología", el Curso de lingüística general ubica la lengua como uno de los sistemas sígnicos más importante del hombre; no obstante, parece poner a la Semiología, pese a recordar que aún es muy pronto para ello, por encima de la Lingüística cuando afirma que:

La lengua es un sistema de signos que expresan ideas, y por eso comparable a la escritura, al alfabeto de los sordomudos, a los ritos simbólicos, a las formas de cortesía, a las señales militares, etc., etc. Solo que es el más importante de todos esos sistemas.

Se puede, pues, concebir una ciencia que estudie la vida de los signos en el seno de la vida social. Tal ciencia sería parte de la Psicología social, y por 
consiguiente de la Psicología general. Nosotros la llamaremos Semiología (del griego sçmeîon 'signo'). Ella nos enseñará en qué consisten los signos y cuáles son las leyes que los gobiernan. Puesto que todavía no existe, no se puede decir qué es lo que ella será; pero tiene derecho a la existencia, y su lugar está determinado de antemano. La Lingüística no es más que una parte de esta ciencia general. Las leyes que la Semiología descubra serán aplicables a la Lingüística, y así es como la Lingüística se encontrará ligada a un dominio bien definido en el conjunto de los hechos humanos (De Saussure, 1945, p. 43).

Una discusión interesante: poner la Semiología como ciencia de la que se desprende la Lingüística; posteriormente, el asunto tomará visos antónimos: será la Lingüística la regente de la Semiología. Hoy, podemos hablar de la Semiolingüística, presente en planes de estudios especializados y tendientes a concebir el lenguaje y la lengua como un hecho lingüístico y simbólico. La semiosfera ha permitido contribuciones importantes; por ejemplo, al concepto de competencia comunicativa, porque le ha impreso el mundo sígnico-simbólico que es parte de cada acto comunicativo. De hecho, con el advenimiento de la Textolinguística, se supera el binomio "emisor-receptor" y el principio de la imagen como unidad de pensamiento, para pasar al "locutor-interlocutor" y al referente como elemento genérico del pensamiento y como posible contenido del mismo.

\section{Elementos fundantes del estructuralismo:}

\section{A manera de conclusiones}

Para cerrar estas reflexiones, en el ámbito de una clase de estructuralismo lingüístico, leamos algunas afirmaciones cumbres en torno del estructuralismo lingüístico, como pilar de la ciencia del lenguaje:

Con el término de estructuralismo, se caracteriza, en especial, los tratados humboldtianos, en donde se considera la lengua como un organismo internamente estructurado. A partir de la concepción del ginebrino Ferdinand De Saussure (18571913), plasmada en su Curso de Lingüística general (1916), realizada pos sus discípulos, principalmente, por Charles Bally y Albert Sechehaye, la Lingüística [como se afirmó arriba] adquiere estatus de ciencia. Dentro de la perspectiva estructuralista aparecen unos principios generales como: la naturaleza del signo lingǘstico, las dicotomías significado-significante, lengua-habla, sincronía-diacronía, sintagmaparadigma; el valor y la oposición (Corredor y Nieto, 2007, pp. 83-96).

Las dicotomías son un elemento esencial en el estudio de la ciencia del lenguaje; de hecho su objeto y aplicaciones han llegado hasta las lides de la Lingüística aplicada:

Los profesores de las lenguas extranjeras y los estudiosos del lenguaje probablemente aceptarán sin ningún tipo de reparo que la metodología dicotómica 
de la Lingüística general y de la Lingüística aplicada ha sido muy útil e iluminadora en la enseñanza de lenguas extranjeras. Por ejemplo, la presentación dual de "significante/significado", "sincronía/diacronía", "lengua/habla[, etc., que debemos a Saussure, y otras más recientes como "competencia/actuación", "discurso/texto", etc., han servido para proyectar más luz sobre el sendero metodológico que lleva a un mejor conocimiento de un fenómeno llamado lenguaje, así como a una comprensión más profunda de su análisis y de su adquisición y aprendizaje" (Alcaraz, 1993, p. 21, citado por Romero, 2012).

Y sobre el objeto y tipificación de la Lingüística:

La Lingüística es la ciencia del lenguaje articulado. También se define como el estudio científico del lenguaje.

Como el objeto de esta ciencia es estudiar el lenguaje humano, los lingüistas -de acuerdo con sus fines y los intereses que los guían para sus investigaciones- han originado una serie de modalidades o especializaciones de la misma en:

a) general o teórica; como estudio abstracto de la comunicación oral, sin concreción necesaria a una lengua;

b) comparativa, sobre las diferencias o afinidades entre las lenguas;

c) diacrónica o histórica; en cuanto a la evolución en el tiempo entre una o diversas lenguas;

d) sincrónica o descriptiva; dedicada, especialmente, a fijar los límites que definen una lengua, actual o pretérita, en todos sus niveles;

e) aplicada a la enseñanza, o como tributaria de cualquier otra ciencia relacionada con la Lingüística (Ruiz y Miyares, 1975, p. 8).

¿Y por qué estructuralismo?:

[Por que la lengua es un sistema de sistemas]

Así, en la oración: Leonel maneja el tractor con destreza, observaremos cómo todo en la lengua está organizado en sistema.

a) La estructura en la oración: es sujeto (Leonel) lo que no es predicado (maneja el tractor...)

b) El valor del verbo (maneja) surge de su relación con las demás partes de la oración: sustantivo, preposición, artículo, etc.

c) Los fonemas forman las palabras oponiéndose a otros fonemas de su sistema (maneja está formado por los fonemas $/ \mathrm{m}+\mathrm{a}+\mathrm{n}+\mathrm{e}+\mathrm{j}+\mathrm{a} /$. Si cambiamos o conmutamos cualesquiera de estos fonemas por otros, se pierde el significado de la palabra maneja: $(m+a+n+\boldsymbol{i}+j+a /)$. (Ruiz y Miyares, 1975, p. 8 ). 
Después de estas reflexiones podemos colegir que, definitivamente, lo estructuralista en el lenguaje tiene gran actualidad; los niveles de análisis lingüístico, la dicotomía significante/significado, lo lineal y lo modular de la lengua: sintagmático/paradigmático, el lenguaje y la lengua, y con ellos el habla; la interdisciplinariedad del lenguaje, la inclusión de la lengua en la mayoría de facetas vitales, por citar pocos casos, más los aspectos, ampliaciones, conceptos, tareas y niveles sumados por el generativismo y por la Textolingüística, siguen utilizándose hoy para elucidar eventos, componentes, objetos y elementos consustanciales con la lengua; así mismo, las dicotomías propias del estructuralismo lingüístico son la base insoslayable de la lingüística actual porque las mismas cumplieron un papel epistemológico sustancial en la génesis y la consolidación de la Lingüística como ciencia que, pronto, será centenaria.

\section{Referencias bibliográficas}

Alcaraz varó, E. (1993). La Lingüística y la metodología didáctica de las lenguas extranjeras. En: García Hoz, V. (Director). (1993). Enseñanza y aprendizaje de las lenguas modernas. Madrid: Rialp. En: ROMERO F., César (2012). "La Lingüística, al servicio del aprendizaje de las lengua", ponencia presentada en el XXVII Congreso Nacional y I Internacional Lingüística, Literatura y Semiótica, Tunja, Uptc, 2012.

Bernal Leongómez, J. (2008). Panorama de lingüistas del siglo XX. Bogotá: Instituto Caro y Cuervo.

Corredor Tapias, J., Nieto Ruiz, L. F. (2007). Un vistazo a los pilares de la Lingüística moderna: Saussure, Chomsky y Van Dijk. Del estructuralismo a la Linguística textual. En: Cuadernos de Lingüística Hispánica, n ${ }^{\circ}$ 9, pp. 83-96. Tunja: Uptc.

De Saussure, F. (1945). Curso de Lingüística general. Buenos Aires: Losada.

Del castillo M., N. (1984). Testimonios del uso de 'vuestra merced', 'vos' y tu' en América (15001650). En: THESAURUS, Boletín del Instituto Caro y Cuervo, Tomo XXXVII, No. 3, pp. 602-644.

Mahecha, M. Á. (2005). Ferdinand De Saussure. Écrits de linguistique générale. Sección Reseñas de Forma y Función, n. 16, pp. 310-323. Bogotá: Universidad Nacional de Colombia.

Robins, R.H. (2000). Breve historia de la Lingüística. Madrid: Cátedra.

Rosenblat, Á. \& Sanabria, A. (1968). Rectifique usted sus conocimientos gramaticales. Tunja: Uptc, la Rana y el Águila.

Ruiz, J. V.; Miyares, E. (1975). Ortografía teórico práctica. Con una introducción lingüística. La Habana: Pueblo y Educación. 